NASA/TM-2000-209954
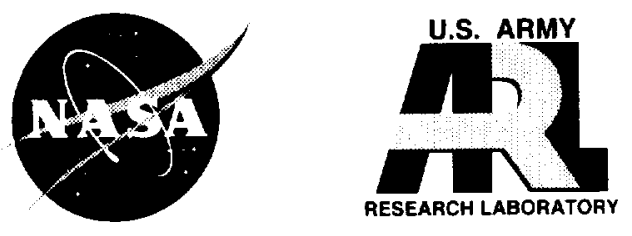

\title{
Lubrication System Failure Baseline Testing on an Aerospace Quality Gear Mesh
}

Robert F. Handschuh

U.S. Army Research Laboratory, Glenn Research Center, Cleveland, Ohio

Wilfredo Morales

Glenn Research Center, Cleveland, Ohio 
Since its founding, NASA has been dedicated to the advancement of aeronautics and space science. The NASA Scientific and Technical Information (STI) Program Office plays a key part in helping NASA maintain this important role.

The NASA STI Program Office is operated by Langley Research Center, the Lead Center for NASA's scientific and technical information. The NASA STI Program Office provides access to the NASA STI Database, the largest collection of aeronautical and space science STI in the world. The Program Office is also NASA's institutional mechanism for disseminating the results of its research and development activities. These results are published by NASA in the NASA STI Report Series, which includes the following report types:

- TECHNICAL PUBLICATION. Reports of completed research or a major significant phase of research that present the results of NASA programs and include extensive data or theoretical analysis. Includes compilations of significant scientific and technical data and information deemed to be of continuing reference value. NASA's counterpart of peerreviewed formal professional papers but has less stringent limitations on manuscript length and extent of graphic presentations.

- TECHNICAL MEMORANDUM. Scientific and technical findings that are preliminary or of specialized interest, e.g., quick release reports, working papers, and bibliographies that contain minimal annotation. Does not contain extensive analysis.

- CONTRACTOR REPORT. Scientific and technical findings by NASA-sponsored contractors and grantees.
- CONFERENCE PUBLICATION. Collected papers from scientific and technical conferences, symposia, seminars, or other meetings sponsored or cosponsored by NASA.

- SPECIAL PUBLICATION. Scientific, technical, or historical information from NASA programs, projects, and missions, often concerned with subjects having substantial public interest.

- TECHNICAL TRANSLATION. Englishlanguage translations of foreign scientific and technical material pertinent to NASA's mission.

Specialized services that complement the STI Program Office's diverse offerings include creating custom thesauri, building customized data bases, organizing and publishing research results... even providing videos.

For more information about the NASA STI Program Office, see the following:

- Access the NASA STI Program Home Page at http://www.sti.nasa.gov

- E-mail your question via the Internet to help@sti.nasa.gov

- Fax your question to the NASA Access Help Desk at (301) 621-0134

- Telephone the NASA Access Help Desk at (301) 621-0390

- Write to: NASA Access Help Desk NASA Center for AeroSpace Information 7121 Standard Drive Hanover, MD 21076 
NASA/TM-2000-209954
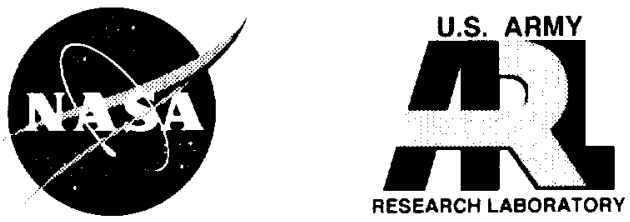

\section{Lubrication System Failure Baseline Testing on an Aerospace Quality Gear Mesh}

Robert F. Handschuh

U.S. Army Research Laboratory, Glenn Research Center, Cleveland, Ohio

Wilfredo Morales

Glenn Research Center, Cleveland, Ohio

Prepared for the

2000 Design Engineering Technical Conferences and Computers and Information in Engineering Conference sponsored by the American Society of Mechanical Engineers Baltimore, Maryland, September 10-13, 2000

National Aeronautics and

Space Administration

Glenn Research Center 
Available from

NASA Center for Aerospace Information 7121 Standard Drive

National Technical Information Service 5285 Port Royal Road Springfield, VA 22100

Hanover, MD 21076

Price Code: $\mathrm{A} 03$

Price Code: A03 


\title{
LUBRICATION SYSTEM FAILURE BASELINE TESTING ON AN AEROSPACE QUALITY GEAR MESH
}

\author{
Robert F. Handschuh \\ Army Research Laboratory \\ National Aeronautics and Space Administration \\ Glenn Research Center \\ Cleveland, Ohio 44135 \\ Wilfredo Morales \\ National Aeronautics and Space Administration \\ Glenn Research Center \\ Cleveland, Ohio 44135
}

\begin{abstract}
Aerospace drive systems are required to survive a loss-oflubrication test for qualification. In many cases emergency lubrication systems need to be designed and utilized to permit the drive system to pass this difficult requirement. The weight of emergency systems can adversely affect the mission capabilities of the aircraft. The possibility to reduce the emergency system weight through the use of mist lubrication will be described. Mist lubrication involves the delivery of a minute amount of a lubricant as a vapor or fine mist in flowing compressed air to rubbing surfaces. At the rubbing surface, the vapor or mist reacts to form a solid lubricating film. The aim of this study was to establish a baseline for gear behavior under oil depleted conditions. A reactive vapor-mist lubrication method is described and proposed as a candidate emergency lubrication system.
\end{abstract}

\section{INTRODUCTION}

The capability of aerospace gearboxes to operate in an emergency, or loss-of-lubrication situation is of extreme importance. In aviation applications the main rotor gearbox is required to operate for at least a 30-minute period during the emergency or main lubrication system failure mode. To operate successfully for this period of time, an emergency lubrication system may be required. When a separate system is required, the aircraft performance suffers from lost payload due to the additional systems weight. During the qualification testing of an aviation gearbox the emergency is simulated by draining the primary lube system while the gearbox is operating thusly initiating the start of the test. The gearbox successfully passes this requirement when a scripted emergency flight scenario (rotational speed, torque, and time at these conditions) is completed by the gearbox.

One of the reasons that some aviation gearboxes require special emergency lubrication systems is due to the general design philosophy to minimize the weight of the drive system without adversely affecting its structural strength. The gear-shafting systems for these applications typically have the gear teeth and rim connected to the shaft via thin webs. With this design philosophy the ability for the components to store and disperse heat created by the drive system is very minimal.

Idler gears can be especially susceptible to thermal problems. The gear teeth on idler gears engage twice and endure two thermal pulses per revolution, one on each side of the tooth separated by one half of a revolution. The idler has twice as much heat per revolution as an input or output gear in the gear train. Multiple engagements also occur in a planetary gear train where the sun gear typically has multiple thermal pulses per revolution as do the planet gears.

The pitch line speed of the gearbox affects the ability of the gearbox to survive a main lubrication system failure for a 30-minute period. The speed of the gear train affects the heat that is generated due to normal sliding action of meshing gears. The heat created due to this mechanism is also greatly affected by the friction in the lubrication-starved contacts once the primary lubrication system has failed.

The emergency capability of the drive train is traditionally attained through an expensive trial-and-error approach that is usually determined long after a given design has already been chosen. This complicates the final design and has a severe impact on the costs to achieve success, especially if major modifications to the design are necessary.

A minimal amount of information on prior work in this area of study is available in the open literature. This is due in part to the proprietary nature of most studies. Some studies have been 
published such as Townsend et al., 1991, however the amount of information available has been limited. A recent study showed that special coatings and ethyl-glycol coolant used together were successful and far exceeded the minimum required time necessary to pass a qualifying test (Maret and Varailhon, 1999).

The objective of this work is to investigate the operation of a single mesh test gearbox in emergency or loss-of-lubrication environment. Several tests were performed using the synthetic lubricant used in the normal lubrication system operation to establish a baseline for eventual comparison with organophosphate mist tests. The baseline tests involved: (1) the steady state operation of a spur gearbox under normal lubricating conditions which consisted of a circulating supply of gear oil, (2) primary lubrication system shutdown to the gearbox simulating a loss of oil operation, and (3) continued operation of the oil depleted gearbox for an extended period. Temperatures measured during testing are reported. At test conclusion, the gear teeth were inspected visually and then examined using $\mathrm{X}$-ray photoelectron spectroscopy (XPS). These results are reported in this paper.

\section{EMERGENCY LUBRICATION METHODS}

An emergency gearbox lubrication system should be lightweight, simple in design, and provide sufficient lubrication to allow a pilot adequate time to land an aircraft. A vapor/mist phase lubrication (VMPL) system meets these conditions. The concept for VMPL involves the delivery of organic molecules, via a carrier gas such as air, to rubbing components such as ball bearings or gear teeth (figure 1). At the rubbing surfaces, several things can happen depending on the chemical nature of the organic molecules. For example, a lubricious graphitic deposit can be generated at rubbing surfaces if a hydrocarbon gas, such as ethane, is delivered in a nitrogen carrier gas. Lauer et al., 1990, have conducted numerous studies on this gaseous breakdown method. Another method studied by Wedeven, 1996, involves the vapor delivery of a perfluoroether liquid to rubbing surfaces using a nitrogen or air carrier. The perfluoroether vapor condenses on
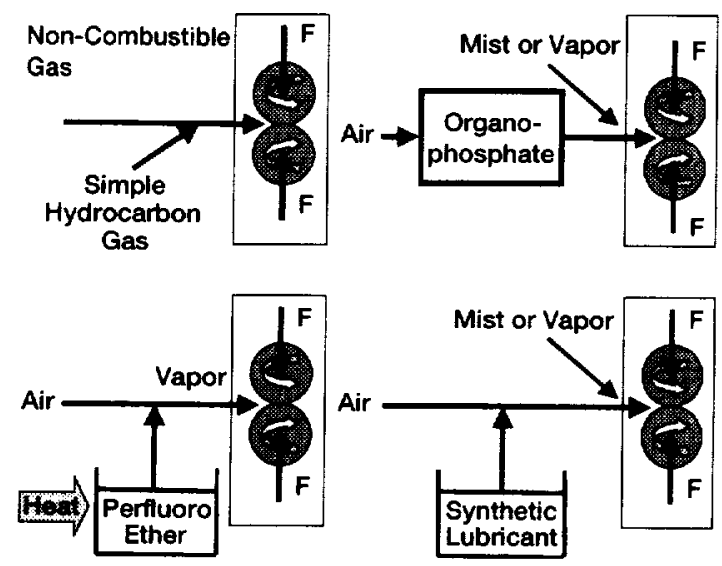

Figure 1.-Comparison of possible emergency lubrication systems. surfaces resulting in a thin lubricating film. The reactive vapor/ mist phase method described by Graham and Klaus, 1985, consists of the delivery of organophosphate molecules, either as a vapor or a fine mist in an air carrier, to rubbing surfaces where they react with surface metal generating a metal phosphate/ pyrophosphate lubricating deposit. This is similar to the mist delivery of synthetic lubricant used in this baseline study.

Each of these methods (figure. 1) has its pros and cons. For the gaseous breakdown method a simple hydrocarbon gas is used, but the aircraft must carry cylinders of compressed hydrocarbon gas and nitrogen. The nitrogen carrier is needed to avoid combustion of the hydrocarbon gas. In addition, the load carrying capacity of the graphitic material is not high. All that is required for the vapor condensation method is a heat source to vaporize the perfluoroether liquid. However, the perfluoroether has a high boiling point (it takes time to raise its temperature), it is very expensive, and can cause severe corrosion problems. Of the three methods, the reactive VMPL method closely meets the requirements for an emergency backup lubrication system. Compressed air can be used to immediately activate a small misting unit containing a liquid organophosphate. The compressed air, containing the mist, can then be directed to an oil depleted gearbox. The organophosphate molecules react with the gear teeth surfaces to form a lubricious deposit possessing excellent load carrying capacity. Continued reaction, however, of the organophosaphate with gear teeth will eventually lead to surface wear.

\section{DESCRIPTION OF TEST FACILITY}

Gear Rig: The facility used to conduct the tests reported herein were conducted in the NASA Glenn Spur Gear Fatigue Rig described by Townsend, 1991. The facility, shown in figure 2 , is a closed-loop torque-regenerative facility. Torque in the system is achieved using high pressure oil, the same oil as used to lubricate the gears, inside one of the slave gears that rotates the

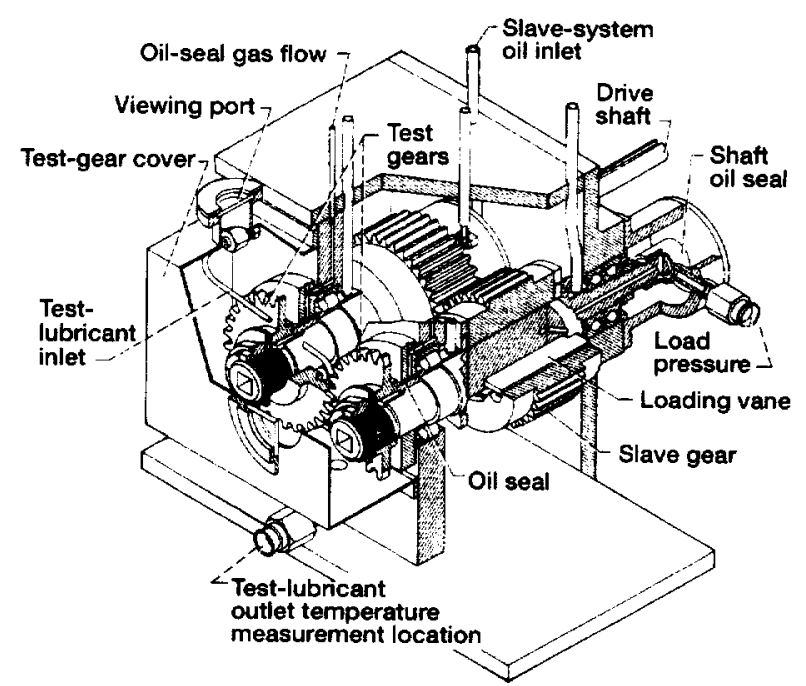

Figure 2.-Spur gear fatigue rig used for conducting tests. 
TABLE I.-SPUR GEAR DATA

[Gear tolerance per AGMA class 12.]

\begin{tabular}{|c|}
\hline 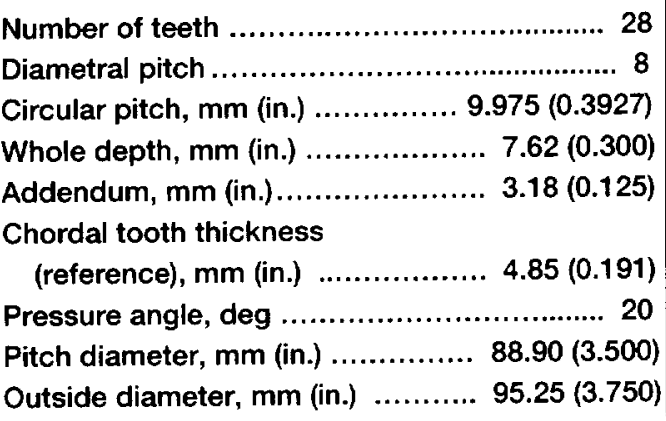 \\
\hline
\end{tabular}

gear relative to the shaft that positions it. The relative motion of the gear to the shaft controls the magnitude of torque in the closedloop system.

The test gears were installed such that approximately one-half of the gear tooth face width was under load. By conducting the tests in this manner, a high amount of contact load is applied and up to twice as many tests could be run using the same set of gears (four instead of two tests). The facility has typically been used for fatigue testing using a Hertizian contact stress of $1.7 \mathrm{GPa}$ $(248 \mathrm{ksi})$. The facility when operated at this level of load and at $10000 \mathrm{rpm}$ transmits $75 \mathrm{~kW}$ (100 hp) in the closed-loop.

The gears utilized for the tests reported herein were the same design as that used for conducting gear fatigue tests (table I). The gears were made from AISI 9310 gear steel. All gears tested were randomly selected from a single manufacturing lot. The lubricant used for all of the normal operation of gearbox, the high pressure oil of the closed-loop torque actuator, and for the mist lubrication was a synthetic paraffinic oil with a extreme pressure additive ( $5 \mathrm{vol} \%$ : phosphorous, $0.03 \mathrm{vol} \%$; sulfur, $0.93 \mathrm{vol} \%$ ).

During the initial operational mode before conducting a loss-oflubrication test, a single $0.51 \mathrm{~mm}(0.020 \mathrm{in}$.) lubricating jet impinged on the gear teeth just prior to going into mesh. Modifications to the lubrication system for the oil-off and vapor/mist lubrication tests are shown in figure 3. A pair of valves would be manually operated to go from normal to the loss-of-lubrication condition. When the system was operated in the loss-of-lubrication mode, the outlet of the gearbox from the test gears was attached to the facility ventilation.

Nearly all the test to be described in this report were attained after the gears were first worn-in (operation at reduced load for at least one hour at $10000 \mathrm{rpm}$ ), then further run at full conditions for at least another hour prior to making adjustments in the load for the test to be run. Steady state conditions were attained in each test prior to altering the lubrication arrangements for the test to be run.

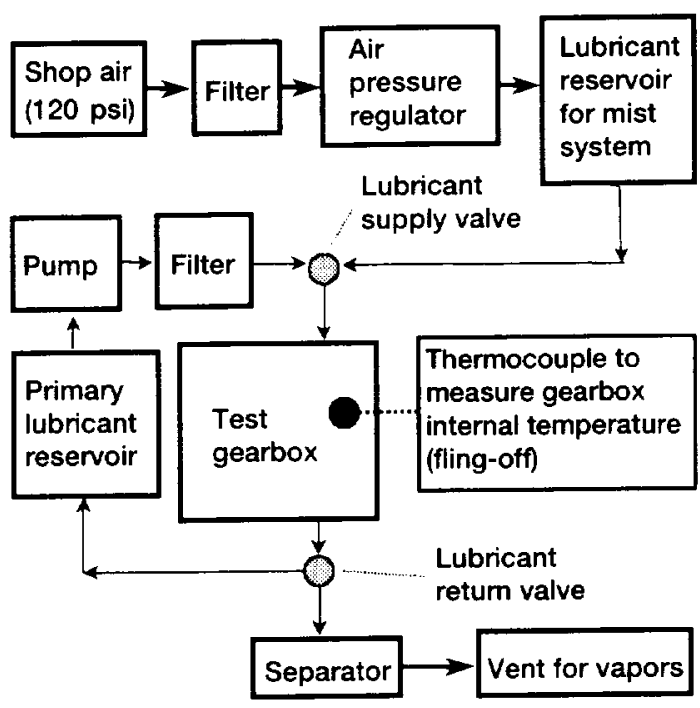

Figure 3.-Schematic of lubrication system.

The principal sensor was a thermocouple at the out of mesh position (so called fling-off temperature). Data was recorded with a laboratory computer, usually at 30 second intervals. Other indicators such as the vibration and noise levels were observed but are not reported in this study.

As mentioned earlier, the facility torque is applied by applying high-pressure oil to load vanes inside one of the slave gears. The torque applied had nearly a linear relationship over the load pressure range of 0.34 to $1.72 \mathrm{MPa}$ (50 to $250 \mathrm{psi}$ ). This was verified by a static torque calibration performed before the test program. For the full loading pressure of $1.72 \mathrm{MPa}$ (250 psi) a torque of $\sim 71.9 \mathrm{~N} \bullet \mathrm{m}(53 \mathrm{ft} \bullet \mathrm{lb})$ is applied. At this torque using half face width engagement of the teeth results in the maximum contact stress of $1.7 \mathrm{GPa}(248 \mathrm{ksi})$.

Surface Analysis: At the end of one particular test run ( 60 percent of full torque test with mist lubrication applied), a randomly selected tooth was removed from the driver spur gear. The tooth was rinsed with ethanol and dried under a nitrogen gas stream. The gear tooth surface was then analyzed using X-ray photoelectron spectroscopy (XPS). The XPS spectra were acquired on a commercial spectrometer operated at $100 \mathrm{eV}$ pass energy The sample surface was perpendicular to the spectrometer axis and the spectrometer acceptance angle was $\pm 6^{\circ}$. Nonmonochromatized, Al K-alpha X-rays were used. The areas of peaks in the spectra were calculated by subtracting a Shirley background, and the composition of the specimen surface was calculated from the areas by applying sensitivity factors supplied by the instrument manufacturer. Depth profiling of surface films was not attempted in this study. 


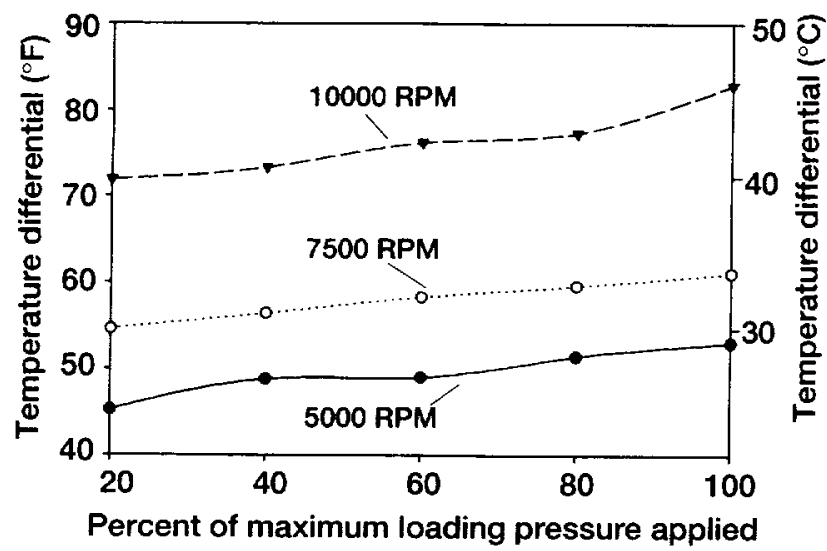

Figure 4.-Effect of speed and load on temperature differential between the oil inlet and oil outlet.

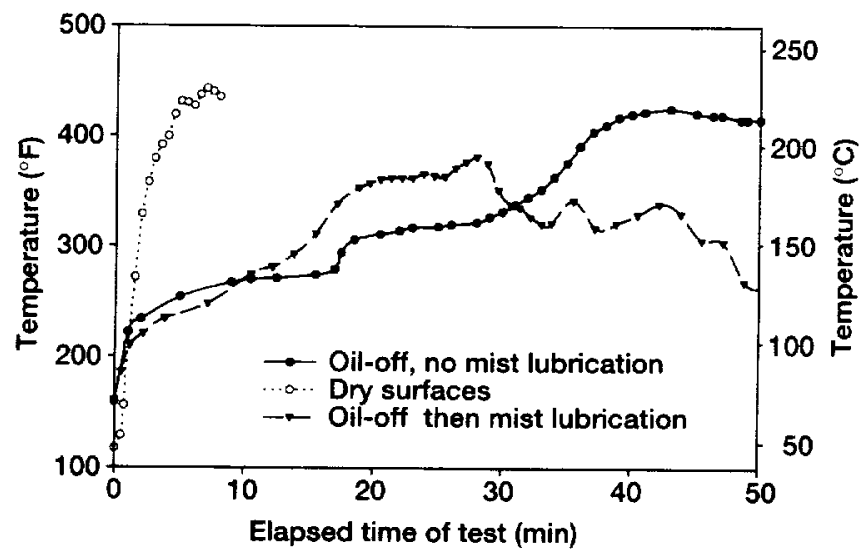

Figure 5.-Effect of lubrication conditions at $1.32 \mathrm{GPa}$ (192 ksi) Hertizian contact stress.

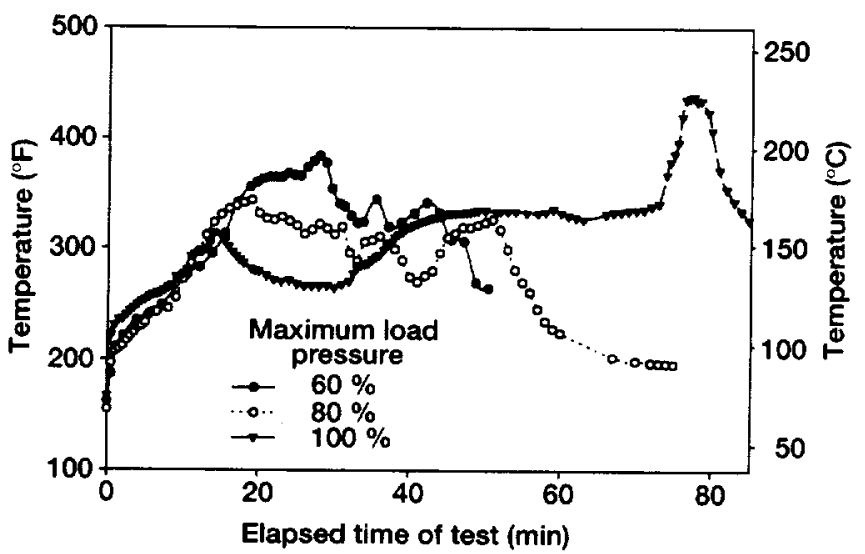

Figure 6.-Effect of load on mist-fed lubrication after primary lubrication was terminated.

\section{TEST RESULTS}

Temperature Results: The first series of test that were conducted were to find the normal operational characteristics of the test gearbox over a wide range of operational conditions. The lubricant flow conditions used during these tests were $0.69 \mathrm{MPa}$ (100 psig) lubricating jet pressure, oil inlet temperature of $38^{\circ} \pm 5^{\circ} \mathrm{C}\left(100^{\circ} \pm 10^{\circ} \mathrm{F}\right)$. The results from these initial tests are shown in figure 4 . In figure 4 , the temperature differential (outlet-inlet temperatures) increases slightly with load, but was affected more by the shaft speed. All tests reported with loss-oflubrication reported herein were conducted at $10000 \mathrm{rpm}$. This results in a pitch line velocity of $46.6 \mathrm{~m} / \mathrm{s}(9163 \mathrm{ft} / \mathrm{min})$ for the gears.

The second series of tests to be described are shown in figure 5 . These tests were run at $1.03 \mathrm{MPa}(150 \mathrm{psi})$ load pressure that results in a maximum contact stress of $1.32 \mathrm{GPa}$ (192 ksi). The lubricating mist system had $0.41 \mathrm{MPa}$ ( $60 \mathrm{psig}$ ) shop air applied for all tests conducted in this study. The flow rate of the mist was measured to be $2.0 \times 10^{-4} \mathrm{~cm}^{3} / \mathrm{sec}\left(3 \times 10^{-6} \mathrm{gpm}\right)$. The results of these three tests are shown in figure 5 . The "dry surface" test gears failed within eight minutes. The term "dry gears" means that the gears were only wetted with lubricant prior to installation. The other two curves show the out of mesh temperature after the lubricating flow was switched either to off or to the mist system. The mist test showed an initial temperature increase beyond that of the oil-off no-mist test. However, the flingoff temperature decreased and ratcheted up and down several times during the test.

The next set of data shown in figure 6 demonstrates the effect of load on fling-off temperature. The data for all three tests followed similar increases for approximately the first 15 minutes. At this point the highest loaded case dropped in fling-off temperature. The same effect was shown in the other tests at reduced load but at longer elapsed time. While all tests were not run to the same length of oil mist lubricating time, some interesting occur-

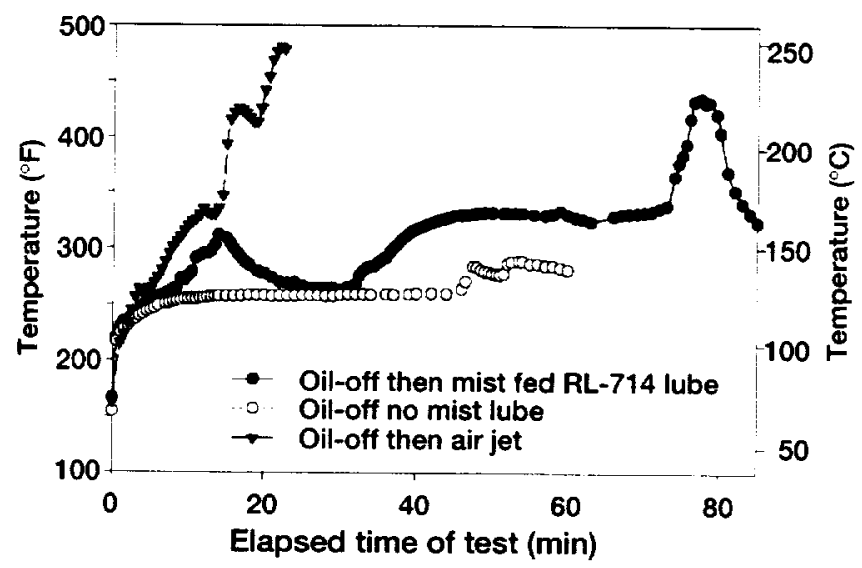

Figure 7.-Effect of lubrication conditions on temperature at $1.71 \mathrm{GPa}(248 \mathrm{ksi})$ Hertizian contact stress. 

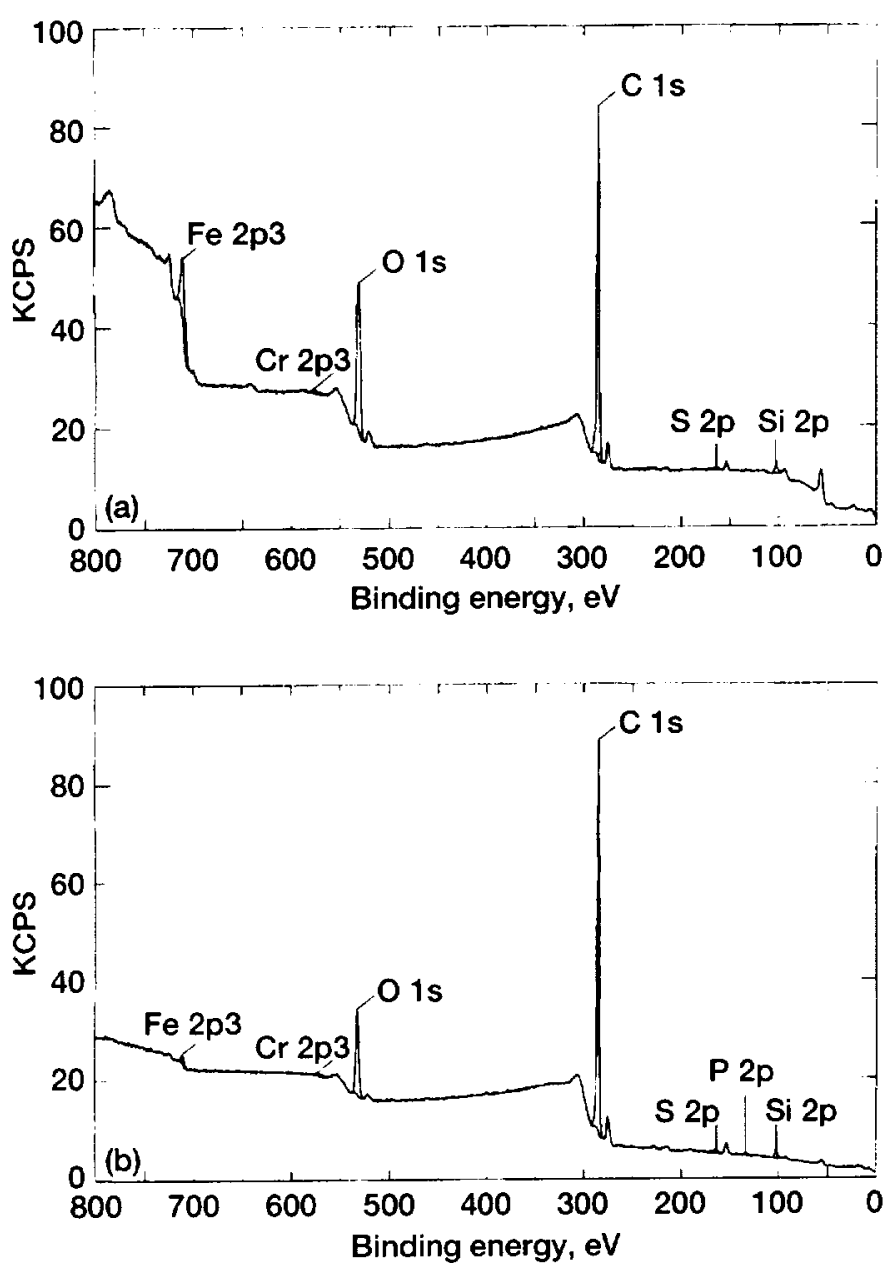

Figure 8.-XPS spectrum of gear tooth surfaces. (a) Wom. (b) Unworn.

rences took place. At the highest load the temperature stabilized and operated in that fashion for about 30 minutes. The medium load test showed a dramatic decrease in temperature after about 50 minutes of operation. It was considered that the drop in temperature might be caused by a reduction in running torque. This was possible because the test rig loading mechanism has limited travel and operates properly only for a limited amount of backlash. If the test gears were excessively worn, the torque would be reduced. To check this possibility, near the end of the test the hydraulic pressure to the load mechanism was increased to the maximum setting, but the temperature did not increase. Therefore, the drop in temperature for the medium load case was caused by a reduction of running torque.

The final test data to be presented are shown in figure 7 . All data of figure 7 were conducted at $10000 \mathrm{rpm}$ and at full load (1.7 GPa ( $248 \mathrm{ksi}$ ) Hertzian contact stress). The effect of no-mist, mist, and only air feeding the jet are shown. As can be seen from this figure, the system ran the best without any mist being supplied. In this case the gears ran without the aid of the mist lubri- cation and relied on the gear oil that remained in the gearbox case after the principal lubricating system was shut off. For the mist fed arrangement, temperature initially went up and was followed by a period of time where the mist and no-mist were alike. The poorest situation is when the air jet was impinged on the gear mesh without the mist. In this arrangement failure of the gear set was reached after 20 minutes.

XPS Results: The gear tooth surface under XPS analysis consisted of two halves. One half was the worn flank that carried the gear load and visually appeared to have a great deal of scoring and metal removal. The other half was the unworn flank that carried no load and visually appeared coated with a dark deposit. Figure $8(a)$ is the XPS spectrum of the worn area of the gear tooth flank. Substantial quantities of iron ( 3.9 percent). oxygen (20.5 percent), carbon ( 72.3 percent) and silicon ( 2.2 percent) were detected. Figure $8(\mathrm{~b})$ is the XPS spectrum of the unworn portion of the tooth flank. In addition to the detection of oxygen (10. 5 percent), carbon ( 85.7 percent) and silicon (2.2 percent), a small quantity of iron $(0.4$ percent $)$ was detected.

A knife-edge was use to scrape off a small amount of deposit from the unworn flank of the gear tooth. This material was spread onto an aluminum ( 99.99 percent pure) foil. This material was then analyzed using XPS. The spectrum revealed the presence of oxygen ( 3.3 percent), carbon ( 94.6 percent), silicon $(0.7$ percent) and the aluminum background source.

\section{DISCUSSION}

The results attained in the prior section will now be discussed with the aid of photographic data taken after the tests. A summary of these results follows.

Lubrication in Starved Environment: The first item to be discussed is the possible mechanisms that are occurring that would lead to a substantial temperature drop once the normal fully lubricated condition has been altered. As was seen in figures 5 to 7 , the temperature decreased after peaking at some elevated temperature. As has been described by others (Anderson and Loewenthal, 1980; Anderson et al., 1984: Coy et al., 1985: Handschuh and Rohn, 1988; Krantz and Handschuh, 1990; Handschuh and Kicher, 1996), the heat generation of meshing gears is principally due to the relative sliding. If the relative sliding is not altered, and if the shaft speed and load remain constant. then the only other possible mechanism to explain the temperature decrease is a decreasing coefficient of friction. Even though the mist flow rate was very low, the interacting surfaces and the combination of pressure and temperature caused a carbonaceous layer to form that resulted in a decrease of the heat being generated and thereby a decease of the temperature measured at the fling-off location. During these tests, as will be seen from the photographs to be discussed, the surface geometry was altered. However, the effect of gear geometry on the magnitude of heat generation should be minimal. 


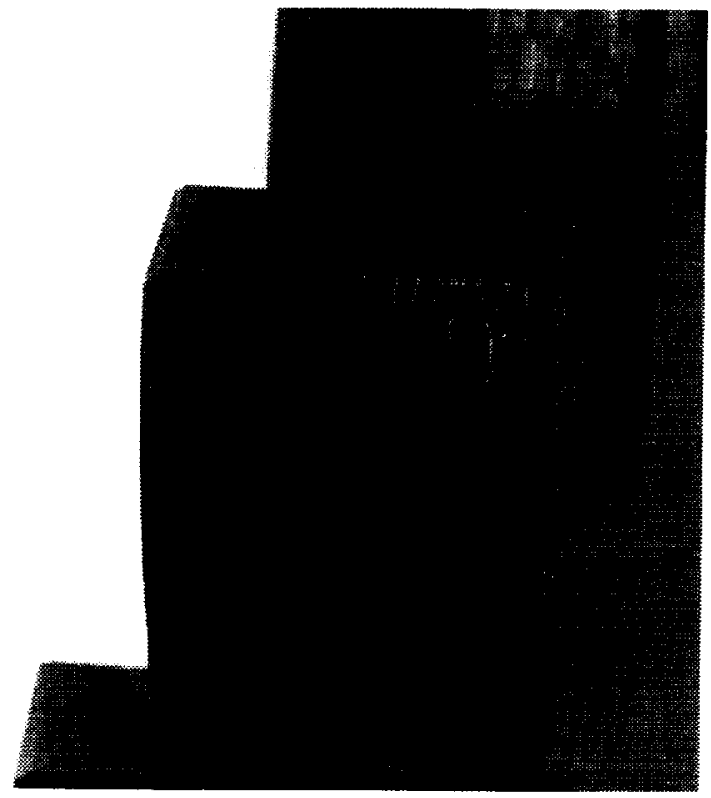

Figure 9.-Post test photograph after operation at $100 \%$ torque, 10000 RPM, and mist lubricated after primary lubrication termination.

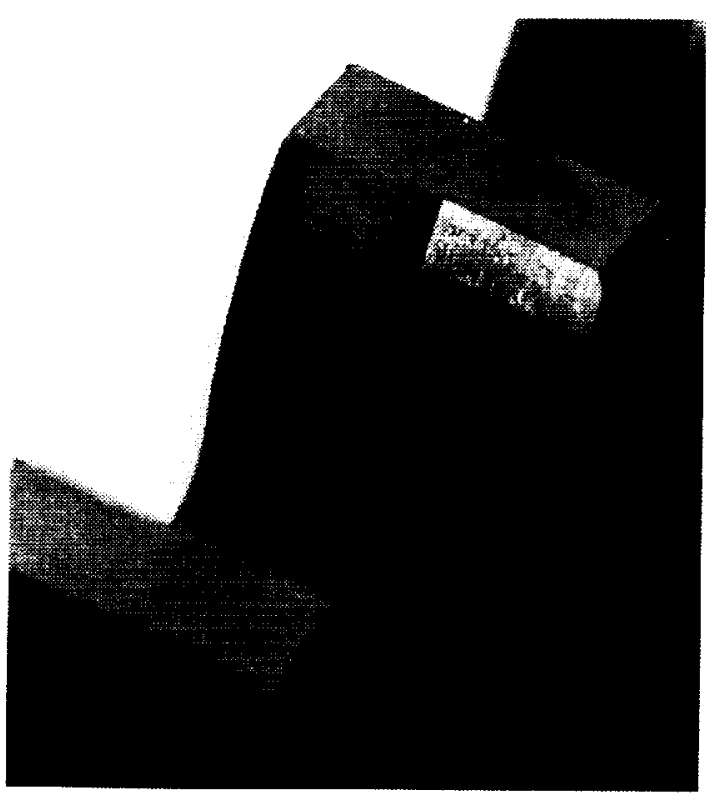

Figure 10.-Post test photograph after operation at $100 \%$ torque, 10000 RPM, and no mist lubricated after primary lubrication termination.

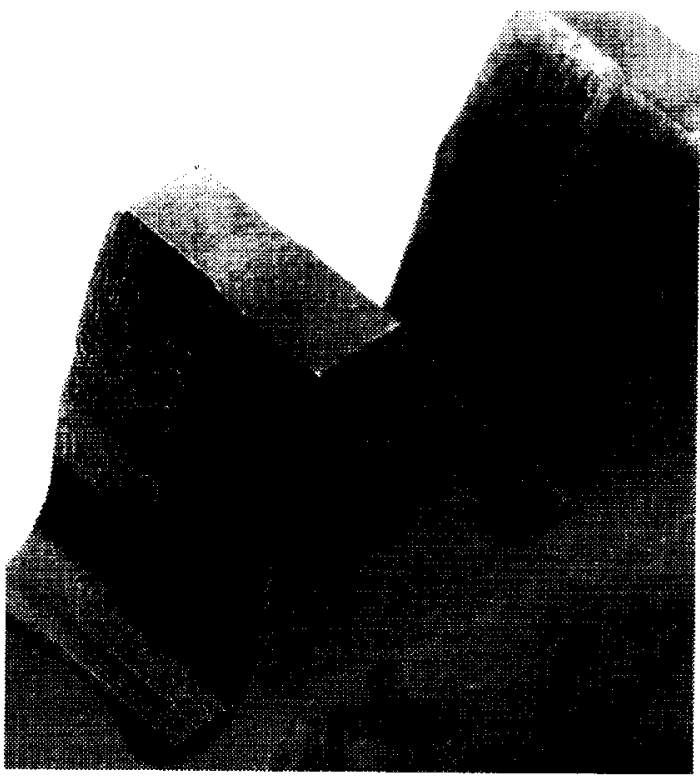

Figure 11.-Post test photograph at $100 \%$ torque, 10000 RPM, and air jet only after primary lubrication termination.

The effect of load on the fling-off temperature was shown in figure 6 . The sudden decrease in temperature (friction) was established at a lower fling-off temperature. Therefore, the imposed load directly affected the onset of the formation of the friction reducing carbonaceous layer.

Photographic Post-Test Evaluation: The photographs to be examined were all from the same gear set used during the test program. Three separate tests were conducted on this same set of gears. The following figures 9 to 11 were tested in the sequence presented in this study. This gear is the one used in the temperature results presented in figure 7 . The first test was an lubricant off then mist fed (figure 9). The surface is severely worn. However, a carbonaceous deposit can be seen on the portion of the gear flank where no surface interaction has taken place. This photograph is similar to others taken, in that the major wear is near the tip and root of the gear flanks and a minimum of wear is at the pitch line.

Figure 10 is the post-test photograph of the driven gear operated with the lubrication shut off and no mist lubrication present. Only the residual lubricant that is normally in the gearbox between inlet and exit was present. This amount of fluid was found by measurement to be $-33 \mathrm{ml}(0.009 \mathrm{gal})$. As can be seen from the photograph, the surface experienced a minimal amount of wear and would have been able to continue operation. This test begs the question, why did this arrangement work better than the system where the misted lubricant was permitted to flow, even at a 
greatly reduced amount? This can be at least partially understood by examination of the next photograph.

In figure 11 the gearset was exposed to lubricant off conditions with only air being fed to the jet at the same pressure used when lubricant was added to the air stream. The photograph shows the severe wear that occurred. Note there is no carbonaceous deposit anywhere on the unloaded portion of the gear tooth flank as had been seen in the other photographs. As was seen in figure 7 , the temperature reached a very high value in a relatively short amount of time. Therefore the lubricant that was initially in the gearbox was pushed out the lubricant drain from the gearbox due to the presence of the air jet. When the air or mist jet was applied through the lubricating jet, the residual oil present was reduced. If the oil-off test without air or oil mist had been permitted to operate for an extended period, until depletion of the residual oil, the gears would have eventually followed the same pattern as the others, and severe wear would have eventually occurred.

XSP Discussion: Comparison of the XPS spectra indicates a substantial carbonaceous deposit (containing oxygen) formed on the surface of the unworn half of the gear tooth. This is evident by the detection of the small amount of iron on the unworn tooth surface and total absence in the scraped deposit. While iron is clearly detected on the worn surface, the carbonaceous material is also detected. One can suggest that at elevated temperatures, gear oil droplets are adsorbed on the gear teeth and decompose to a lubricious, carbonaceous deposit. This deposit would then be continually worn away and reformed during operation.

\section{CONCLUSIONS}

A baseline study has been conducted to investigate the effect of lubrication starvation on the performance of a single-mesh spur gearbox that has components made to aerospace tolerances. A reactive vapor/mist lubrication method was described and proposed as a candidate emergency lubrication system. The conclusions that can be drawn from experiments of this study are the following:

1. Operation with primary lubrication system failure can be long, provided a sufficient amount of lubricant continues to impinge on the gear surfaces whether due to the windage of the residual oil in the gearbox or by misting jet.

2. A friction reducing mechanism is formed due to the lubricious carbonaceous deposit at the meshing surfaces. The onset of this deposit and the resultant reduction in heat generation (friction) is affected by the amount of load being transmitted.

\section{REFERENCES}

Anderson, N. and Loewenthal, S.: "Spur-Gear Efficiency at Part and Full Load," NASA TP-1622, AVRADCOM TR 79-46, 1980.

Anderson, N., and Loewenthal, S., and Black. J.: "An Analytical Method to Predict Efficiency of Aircraft Gearboxes," NASA TM-83716, AIAA-84-1500, June 1984.

Coy, J., Townsend, D., and Zaretsky, E.: "Gearing," NASA RP-1152, AVSCOM TR-84-C-15, Dec. 1985.

Graham, E.E., and Klaus, E.E., "Lubrication from the Vapor Phase at High Temperatures," ASLE Transactions, 29, 2. pp 229-234, (1985).

Handschuh, R., and Kicher, T.: "A Method for Thermal Analysis of Spiral Bevel Gears," Journal of Mechanical Design, Vol. 118. 1996.

Handschuh, R. and Rohn, D.: "Efficiency Testing of a Helicopter Transmission Planetary Reduction Stage," NASA TP-2795, 1988.

Krantz, T. and Handschuh, R.: "Efficiency Study Comparing Two Helicopter Planetary Reduction Stages," NASA TM-103106, July 1990.

Lauer, J. and Dwyer, S.R., "Continuous High Temperature Lubrication of Ceramics by Carbon Generated Catalytically from Hydrocarbon Gases," Trib. Trans., 33, 4, pp. 529-534, ( 1990 ).

Maret, P., and Varailhon, C.: "Main Gearbox with Higher Survivability and Reliability," 25th European Rotorcraft Forum, Rome, Italy, Sept. 1999.

Townsend, D.: "Improvements in Surface Fatigue Life of Hardened Gears by High Intensity Shot Peening," NASA TM-105678, AVSCOM TR-91-C-042, 1991.

Townsend, D., Coy, J., and Hatvani, B.: "OH-58 Helicopter Transmission Failure Analysis," NASA TM X-71867, 1976.

Wedeven, L.D., "The Concept of Vapor-Condensation Lubrication," Presented at the 51st STLE Annual Meeting. May 19-23, (1996). 


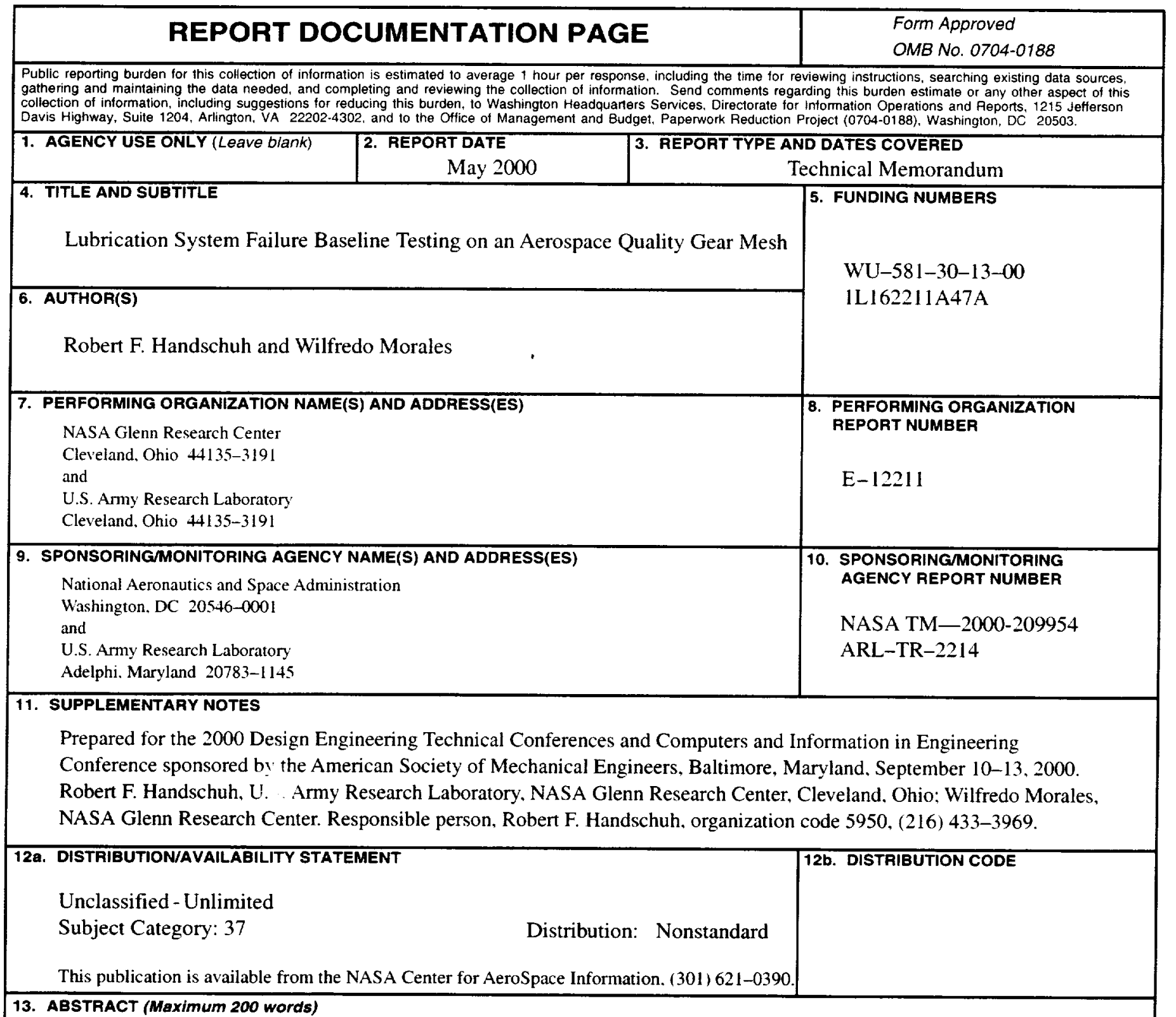

Aerospace drive systems are required to survive a loss-of-lubrication test for qualification. In many cases emergency lubrication systems need to be designed and utilized to permit the drive system to pass this difficult requirement. The weight of emergency systems can adversely affect the mission capabilities of the aircraft. The possibility to reduce the emergency system weight through the use of mist lubrication will be described. Mist lubrication involves the delivery of a minute amount of an organic liquid as a vapor or fine mist in flowing compressed air to rubbing surfaces. At the rubbing surface, the vapor or mist reacts to form a solid lubricating film. The aim of this study was to establish a baseline for gear behavior under oil depleted conditions. A reactive vapor-mist lubrication method is described and proposed as a candidate emergency lubrication system.

\begin{tabular}{|c|c|c|c|}
\hline \multicolumn{3}{|c|}{$\begin{array}{l}\text { 14. SUBJECT TERMS } \\
\text { Gears; Drive; Trains; Lubrication }\end{array}$} & $\begin{array}{l}\text { 15. NUMBER OF PAGES } \\
13 \\
\text { 16. PRICE CODE } \\
\text { A03 }\end{array}$ \\
\hline
\end{tabular}

